\title{
Constituents of Chinese Crude Drug "Wujiapi". IV.1) On the Structure of a New Acetylbiose from Steroidal Glycosides of Bei-Wujiapi ${ }^{2,3}$
}

\author{
Sachiko Kawanishi, Seitchi Sakuma, Hiroko Okino and Junzo Shoji \\ School of Pharmaceutical Sciences, Showa University ${ }^{4}$
}

(Received June 9, 1971)

\begin{abstract}
The chemical structures of two hydrolysis products of the crude glycoside fraction of Chinese crude drug "Bei-Wujiapi (cortex of Periploca sepium BGE.)" were studied. The one product is 4-O-(2-O-acetyl- $\beta$-D-digitalopyranosyl)-D-cymaropyranose and the other is methyl 4-O-(2-O-acetyl- $\beta$-D-digitalopyranosyl $)-\beta$-D-cymaropyranoside.
\end{abstract}

As we reported in the preliminary communication ${ }^{2)}$ a new acetylbiose (I) and its methyl glycoside (II) were isolated from the mild acid hydrolysis products of steroidal glycoside $\mathrm{H}_{1}{ }^{5)}$ or crude glycosidic fraction of methanol extracts of Bei-Wujiapi (cortex of Periploca sepium Bge. (Asclepiadaceae)). The present paper reports the detailed study on the chemical structures of these compounds.

According to the previous paper, ${ }^{5)} n$-butanol soluble fraction of methanol extracts of the crude drug was hydrolysed with $0.05 \mathrm{~N}_{2} \mathrm{SO}_{4}-50 \% \mathrm{MeOH}$. The hydrolysate was examined by thin-layer chromatography (TLC) to show the presence of I and II accompanied with more than twelve products. The isolation of these compounds from the hydrolysate was carried out by column chromatography on silica gel developed with ethyl acetate.

$\mathrm{I}, \mathrm{C}_{16} \mathrm{H}_{28} \mathrm{O}_{9}, \operatorname{mp~} 177^{\circ},[\alpha]_{\mathrm{D}}^{21}+55.7^{\circ}$ (pyridine), ${ }^{6)}$ was obtained as colorless needles from ethyl acetate- $n$-hexane (yield: $0.01 \%$ from the dried crude drug), and showed positive color reactions with aniline hydrogen phthalate, $\mathrm{NH}_{3}-\mathrm{AgNO}_{3}$ (Tollens' reagent), xanthohydrol, and $p$-nitrophenylhydrazine but was negative to $\mathrm{NaIO}_{4}$-benzidine. Another product, II, $\mathrm{C}_{17} \mathrm{H}_{30} \mathrm{O}_{9}, \mathrm{mp} 171^{\circ},[\alpha]_{\mathrm{D}}^{23}+25.5^{\circ}$ (pyridine ${ }^{6)}$ ) was crystallized from ethyl acetate as colorless needles (yield: $0.03 \%$ from the dried crude drug) and gave monoacetate (III) with acetic anhydride in pyridine at room temperature. The color reaction of II was positive to xanthohydrol but negative to aniline hydrogen phthalate or $\mathrm{NaIO}_{4}$-benzidine.

The study on the nuclear magnetic resonance spectra (NMR) and infrared absorption spectra (IR) of II suggested the presence of one acetyl group (IR $\nu_{\max }^{\mathrm{KBr}} \mathrm{cm}^{-\mathbf{1}}$ : 1750, 1240; NMR $\left.\delta_{\mathrm{TMS}}^{\mathrm{CDCl}_{1}}: 2.003 \mathrm{H}(\mathrm{s})-\mathrm{COCH} \underline{\mathrm{H}}_{3}\right)$, three O-methyl groups $\left(\delta=3.453 \mathrm{H}(\mathrm{s}), 3.483 \mathrm{H}(\mathrm{s}) \times 2-\mathrm{OCH}_{3}\right)$ and two secondary methyl groups $(\delta=1.203 \mathrm{H}(\mathrm{d}, J=6.4 \mathrm{cps}), \quad \delta=1.383 \mathrm{H}(\mathrm{d}, J=6.4 \mathrm{cps})$ $\mathrm{H}-\mathrm{C}^{\prime}-\mathrm{CH}_{3}$ ).

Deacetylation of II with $0.4 \mathrm{~N} \mathrm{KOH}$ afforded the product (IV), $\mathrm{C}_{15} \mathrm{H}_{28} \mathrm{O}_{8}$, which was hydrolysed with $0.05 \mathrm{~N}_{2} \mathrm{SO}_{4}$ under refluxing to give D-cymarose and D-digitalose. The optical rotations of the resulted sugars were measured on the samples collected by preparative TLC.

From the physical and chemical data of the foregoing study, the chemical structure of II was deduced to be a new acetylbiose. The NMR spectra of I and II resembled very closely but the remarkable difference was the presence of one extra O-methyl signal in the later.

1) Phart III: S. Sakuma, H. Ishizone, R. Kasai, S. Kawanishi and J. Shoji, Chem. Pharm. Bull. (Tokyo), 19, $52(1971)$.

2) J. Shoji, S. Kawanishi, S. Sakuma, H. Okino and M. Sano, Chem. Pharm. Bull. (Tokyo), 16, 2308 (1968).

3) According to chinese pronounciation, Pei-Wujiapi, reported in the preliminary communication ${ }^{2)}$ was revised to Bei-Wujiapi in this paper.

4) Location: Hatanodai, Shinagawa-ku, Tokyo.

5) S. Sakuma, S. Kawanishi, J. Shoji and S. Shibata, Chem. Pharm. Bull. (Tokyo), 16, 326 (1961).

6) Some of the signs of optical rotation reported in the preliminary communication ${ }^{2}$ ) were erroneous and they were revised in this paper. 
Taking account of the lack of reducing power in II, it was deduced that II must be the methyl glycoside of I. This assumption was confirmed by refluxing I with anhydrous $0.05 \mathrm{~N}$ $\mathrm{HCl}-\mathrm{MeOH}$ for $30 \mathrm{~min}$ to afford II along with other products. On the other hand, the formation of I from II was established by heating with $0.05 \mathrm{~N} \mathrm{H}_{2} \mathrm{SO}_{4}$ for $15 \mathrm{~min}$. From these interconversions, it was elucidated that II was a methyl glycoside of I and the formation of II from the glycosides of Bei-Wujiapi was caused by methanolic hydrolysis.

On permethylation by Hakomori's method, ${ }^{7)}$ IV gave di-O-methylether (V), $\mathrm{C}_{17} \mathrm{H}_{32} \mathrm{O}_{8}$, $\mathrm{mp} 106^{\circ}$, which was hydrolysed with $0.05 \mathrm{~N} \mathrm{H}_{2} \mathrm{SO}_{4}$ to afford cymarose and 2,4-di-O-methyldigitalose. These sugars were characterised by TLC and gas liquid chromatography (GLC) comparing with the authentic samples.

From the results of the foregoing experiments, the partial structure of II was proposed to be methyl (O-acetyl-D-digitalopyranosyl)-D-cymaroside. The position of an acetyl group in II was examined by the spin-spin decoupling technic and by the chemical method. Irradiation at the center of the doublet signal $(\delta=4.42,1 \mathrm{H}, J=8.0 \mathrm{cps})$ which was assigned to be the signal of anomeric porton of digitalose and that of the quartet signal $(\delta=5.15,1 \mathrm{H}$, $J_{1}=9.8 \mathrm{cps}, J_{2}=8.0 \mathrm{cps}$ ), which was assumed to be the signal of proton on the carbon bearing $\mathrm{O}$-acetyl group, revealed that both signals were coupled each other. From the chemical shift and decoupling data, the quartet signal at $\delta=5.15$ was assigned to the proton of digitalose- $\mathrm{C}_{2}$ on which $\mathrm{O}$-acetyl group was located. On the other hand, the chemical evidence to support the result of NMR observation about the location of the acetyl group of II was given by the characterization (TLC, GLC and mixed fusion) of methyl 4-O-methyl- $\alpha$-D-digitalopyranoside obtained from the hydrolysate of a per-O-methyl ether, (VI), $\mathrm{C}_{\mathbf{1 8}} \mathrm{H}_{\mathbf{3} 2} \mathrm{O}_{9}$, which was derived from II by Kuhn's method.8) Under the condition used for the hydrolysis of $\mathrm{V}$, an acetyl group was eliminated.
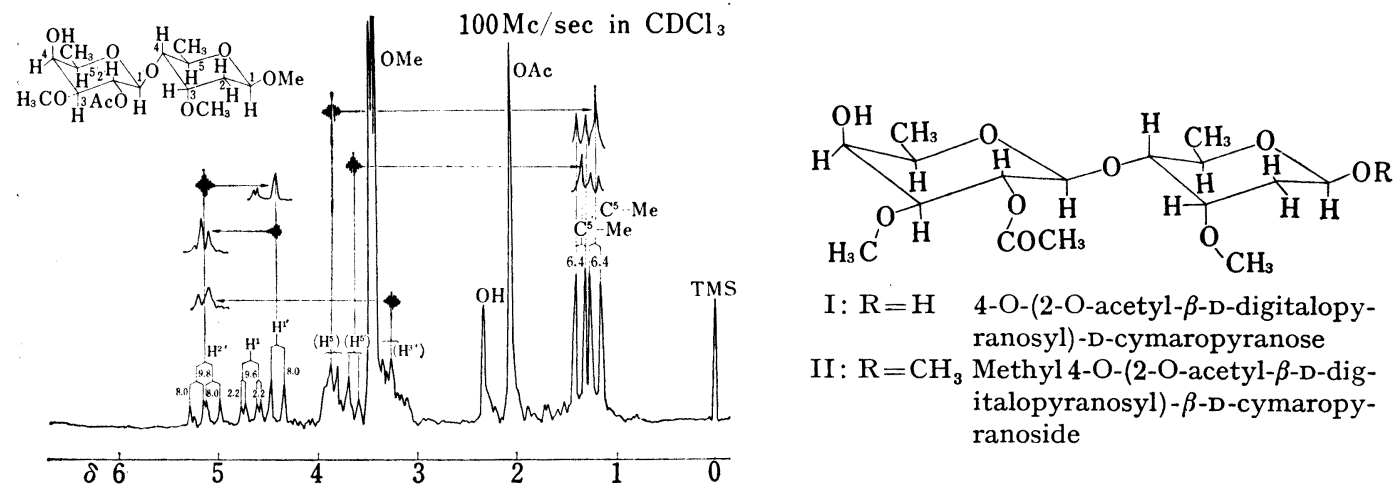

I : $\mathrm{R}=\mathrm{H} \quad 4-\mathrm{O}-(2-\mathrm{O}$-acetyl- $\beta$-D-digitalopyranosyl)-D-cymaropyranose

II : $\mathrm{R}=\mathrm{CH}_{3}$ Methyl 4-O-(2-O-acetyl- $\beta$-D-digitalopyranosyl) - $\beta$-D-cymaropy-

Fig. 1. NMR Spectrum of II

Furthermore, the pyranoid structure of cymarose moiety in I was elucidated by IR spectrum of a lactone (VII), $\mathrm{C}_{16} \mathrm{H}_{26} \mathrm{O}_{9}\left(\nu_{\max }^{\mathrm{CH}_{2} \mathrm{Cl}_{2}} \mathrm{~cm}^{-1}: 1740, \delta\right.$-lactone), which was obtained from I by oxidation with bromine in water. ${ }^{9)}$

The configurations of 2-O-acetyl-D-digitalopyranoside and methyl D-cymaropyranoside in II were all assigned to $\beta$ form from NMR coupling constants of the anomeric protons, $\delta=4.42$ (d, $J=8 \mathrm{cps}$, digitalose) and $\delta=4.68$ (q, $J_{1}=9.6 \mathrm{cps}, J_{2}=2.2 \mathrm{cps}$, cymarose).

The total structure of I was concluded to be 4 -O-(2-O-acetyl- $\beta$-D-digitalopyranosyl)-Dcymarose and II was methyl 4-O-(2-O-acetyl- $\beta$-D-digitalopyranosyl)- $\beta$-D-cymaroside.

7) S. Hakomori, J. Biochem. (Tokyo), 55, 205 (1964).

8) R. Kuhn, Angew. Chem., 67, 32 (1955).

9) W.B. Neely, Advances Carbohydrate Chemistry, 12, 13 (1957); H. Spedding, ibid., 19, 23 (1964). 
Recently H. Allgeiser $\left.{ }^{10 a, b}\right)$ has reported the structure of 4-O-(3-O-methyl-6-deoxy- $\beta$-Dallopyranosyl)-D-oleandrose(=pachybiose) ${ }^{10 a}$ from Pachycarpus lineolatus, ${ }^{11)}$. Gongronema taylorii, ${ }^{12)}$ Dregea volubilis, ${ }^{13)}$ Dregea abyssinica, ${ }^{14)}$ Marsdenia erecta, ${ }^{15)}$ 4-O-(3-O-methyl-6deoxy- $\beta$-D-allopyranosyl)-D-cymarose(=asclepobiose) ${ }^{10 a}$ ) from Ascleopias lilacina, $\left.{ }^{16 a}, b\right)$ Dregea volubilis $^{13)}$ and Dregea abyssinica, ${ }^{14)}$ 4-O-(3-O-methyl-6-deoxy- $\beta$-D-allopyranosyl)-D-digitoxose (=drebyssobiose) ${ }^{10 b}$ from Dregea volubilis ${ }^{13)}$ and Dregea abyssica, ${ }^{14,17)}$ 4-O-( $\beta$-D-thevetosyl)-Dcymarose(=lilacinobiose) ${ }^{\mathbf{1 0 b}}$ ) from Asclepias lilacina ${ }^{\mathbf{1 6} a, b)}$ and Sarcostemma viminale, ${ }^{18)}$ 4-O$(\beta \text {-D-thevetosyl)-D-digitoxose(=viminose })^{10 b}$ ) from Sarcostema viminale ${ }^{18}$ ) and 4 -O-( $\beta$-D-thevetosyl)-D-oleandrose (=marsectobiose) from Marsdenia erecta (Asclepiadaceae).

It is very interesting that the similar bioses, which are composed of 2,6-bisdeoxy-and/or 6deoxysugar, have been found in the plants belonging to the same family, Asclepiadaceae, and they are governed by certain regularity in their sugar sequences. In any case, 6-deoxysugar combines to the more reduced sugar, namely 2,6-bisdeoxysugar. These bioses are assumed to constitute a part of glycosidic linkage, thus it must be noted that the biogenetical study on pregnane glycoside and cardiac glycoside of these plants are very interesting and further investigation will be published in the near future.

\section{Experimental}

All melting points were determined on a Yanagimoto Micro Melting Point apparatus and uncorrected. Molecular weight was measured with a Hitachi Perkin-Elmer Model 115 Mass spectrometer. IR absorption spectra were measured with a Hitachi Model EPI-2. NMR spectra were measured with a Japan Electron Co. JNM. $4 \mathrm{H}-100$ spectrometer with tetramethylsilane as an internal standard. Gas chromatograph used was a Hitachi Model K-53 with a hydrogen flame ionization detector.

Isolation of I and II-Crude glycoside fraction from methanol extracts of Bei-Wujiapi ${ }^{5)}$ was refluxed with $0.05 \mathrm{~N} \mathrm{H}_{2} \mathrm{SO}_{4}-50 \% \mathrm{MeOH}$ for $30 \mathrm{~min}$. The isolation of I and II from the hydrolysate was carried out by column chromatography on silica gel developed with ethyl acetate. The eluate was rechromatographed and recrystallized to give I (Yield: $0.01 \%$ from the dried crude drug) and II (Yield: $0.03 \%$ from the dried crude drug).

Properties of I-I I was recrystallized from AcOEt- $n$-hexane to give colorless needles, $\mathrm{mp} 177^{\circ},[\alpha]_{\mathrm{B}}^{21}$ $+55.7^{\circ}$ ( $c=0.47$ pyridine). Anal. Calcd. for $\mathrm{C}_{16} \mathrm{H}_{28} \mathrm{O}_{9}: \mathrm{C}, 52.74 ; \mathrm{H}, 7.75$. Found: $\mathrm{C}, 52.70 ; \mathrm{H}, 7.78$. IR $v_{\max }^{\mathrm{KBr}} \mathrm{cm}^{-1}: 3400(\mathrm{OH}), 1745,1240$ (ester). NMR $\delta_{\mathrm{TMS}}^{\mathrm{CDCl}}: 1.213 \mathrm{H}(\mathrm{d}, J=6 \mathrm{cps}), 1.363 \mathrm{H}(\mathrm{d}, J=6 \mathrm{cps}), 2.073 \mathrm{H}(\mathrm{s})$, $3.403 \mathrm{H}(\mathrm{s}), 3.523 \mathrm{H}(\mathrm{s}), 4.431 \mathrm{H}(\mathrm{d}, J=8 \mathrm{cps}), 5.091 \mathrm{H}\left(\mathrm{q}, J_{1}=9 \mathrm{cps}, J_{2}=8 \mathrm{cps}\right)$.

Properties of II-II was recrystallized from AcOEt to give colorless needles, mp $171^{\circ}$, sublime, $[\alpha]_{\mathrm{D}}^{23}$ $+25.5^{\circ}$ ( $c=1.10$ pyridine). Anal. Calcd. for $\mathrm{C}_{17} \mathrm{H}_{30} \mathrm{O}_{9}: \mathrm{C}, 53.95 ; \mathrm{H}, 7.99$; mol.wt. 378 . Found: $\mathrm{C}$, 53.42; $\mathrm{H}$, 7.72, mol. wt. 361 . IR $\nu_{\max }^{\mathrm{KBr}} \mathrm{cm}^{-1}: 3550(\mathrm{OH}), 1750,1240$ (ester). UV $\lambda_{\max }^{\mathrm{EtOH}} \mathrm{m} \mu:<210$. NMR $\delta_{\mathrm{TM}}^{\mathrm{CDCl}_{3}}$ : $1.203 \mathrm{H}(\mathrm{d}, J=6.4 \mathrm{cps}) \mathrm{cym} .{ }^{19)}-\mathrm{C}_{5}-\mathrm{CH}_{3}, 1.383 \mathrm{H}(\mathrm{d}, J=6.4 \mathrm{cps}) \operatorname{dig} .{ }^{19)}-\mathrm{C}_{5}-\mathrm{CH}_{3}, 1.4-2.32 \mathrm{H}(\mathrm{m}), \mathrm{cym} .-\mathrm{C}_{2}-\mathrm{H}_{2}$, $2.003 \mathrm{H}(\mathrm{s})$ dig. $-\mathrm{C}_{2}-\mathrm{OCOCH}_{3}, 2.351 \mathrm{H}(\mathrm{s})$ dig. $-\mathrm{C}_{4}-\mathrm{OH}, 3.453 \mathrm{H}(\mathrm{s}) \mathrm{OCH}_{3}, 3.483 \mathrm{H} \times 2(\mathrm{~s}) \mathrm{OCH}_{3}, 4.421 \mathrm{H}(\mathrm{d}$, $J=8.0 \mathrm{cps})$ dig. $-\mathrm{C}_{1}-\mathrm{H}, 4.681 \mathrm{H}\left(\mathrm{q}, J_{1}=9.6 \mathrm{cps}, J_{2}=2.2 \mathrm{cps}\right)$ cym. $-\mathrm{C}_{1}-\mathrm{H}, 5.151 \mathrm{H}\left(\mathrm{q}, J_{1}=9.8 \mathrm{cps}, J_{2}=8.0 \mathrm{cps}\right)$ dig. $-\mathrm{C}_{2}-\mathrm{H}$.

Interconversion of $\mathbf{I}$ and $\mathbf{I I}-\mathrm{I}$ was refluxed with anhydrous $0.05 \mathrm{~N} \mathrm{HCl-MeOH}$ for $30 \mathrm{~min}$ to give cymarose and other by-products. On the other hand II was refluxed with $0.05 \mathrm{~N} \mathrm{H}_{2} \mathrm{SO}_{4}$ for 15 min to give $\mathrm{I}$. Identification was made by comparison of TLC, mixed fusion and IR spectra with an authentic sample.

Acetylation of II-II was acetylated with $\mathrm{Ac}_{2} \mathrm{O}$ in pyridine at room temperature for $48 \mathrm{hr}$. The product was worked up as usual and recrystallized from AcOEt to give colorless needles (III), $\mathrm{mp} 116^{\circ},[\alpha]_{\mathrm{D}}^{28}+\mathbf{2 2 . 4}^{\circ}$ (c=0.98 pyridine). Anal. Calcd. for $\mathrm{C}_{19} \mathrm{H}_{32} \mathrm{O}_{10}: \mathrm{C}, 54.27 ; \mathrm{H}, 7.67$. Found: $\mathrm{C}, 54.29 ; \mathrm{H}, 7.68$. IR $\nu_{\max }^{\mathrm{KBr}} \mathrm{cm}^{-1}$ :


$\left.-\mathrm{C}_{5}-\mathrm{CH}_{3}\right), 1.4-2.52 \mathrm{H}(\mathrm{m})$ cym. $\left.-\mathrm{C}_{2}-\mathrm{H}_{2}\right), 2.003 \mathrm{H}(\mathrm{s})$ dig. $-\mathrm{C}_{2}-\mathrm{OCOCH}_{3}, 2.083 \mathrm{H}(\mathrm{s})$ dig. $-\mathrm{C}_{4}-\mathrm{OCOCH}_{3}, 3.383 \mathrm{H}(\mathrm{s})$

10) a) H. Allegeiser, Helv. Chim. Acta, 51, $311(1968)$; b) H. Allegeiser, ibid., 51, 668 (1968).

11) E. Abisch, CH. Tamm and T. Reichstein, Helv. Chim. Acta, 42, 1014 (1959).

12) K.A. Jaeggi, EK. Weiss, W. Wehrli and T. Reichstein, Helv. Chim. Acta, 50, 1201 (1967).

13) H.H. Sauer, EK. Weiss and T. Reichstein, Helv. Chim. Acta, 49, 1625 (1966).

14) A.S. Bhatnagar, H. Kaufmann, W. Stöcklin and T. Reichstein, Helv. Chim. Acta, 51,117 (1968).

15) A. Saner, C. Zerlentis, W. Stöcklin and T. Reichstein, Helv. Chim. Acta, 53, 221 (1970).

16) a) L. Sawlewicz, E.K. Weiss and T. Reichstein, Helv. Chim. Acta, 50, 504 (1967); b) idem, ibid., 50, 530 (1967).

17) A.S. Bhatnagar, W. Stöcklin and T. Reichstein, Helv. Chim. Acta, 51, 133 (1968).

18) F. Schaub, H. Kaufmann, W. Stöcklin and T. Reichstein, Helv. Chim. Acta, 51, 738 (1968).

19) Abbreviation: cym.=cymarose, dig.=digitalose. 
$\mathrm{OCH}_{3}, 3.453 \mathrm{H}(\mathrm{s}) \mathrm{OCH}_{3}, 3.483 \mathrm{H}(\mathrm{s}) \mathrm{OCH}_{3}, 4.491 \mathrm{H}(\mathrm{d}, J=8 \mathrm{cps}) \operatorname{dig} . \mathrm{C}_{1}-\mathrm{H}, 4.701 \mathrm{H}\left(\mathrm{q}, J_{1}=9.2 \mathrm{cps}, J_{2}=2.2\right.$ cps) cym.- $\mathrm{C}_{1}-\mathrm{H}, 5.191 \mathrm{H}\left(\mathrm{q}, J_{1}=9.8 \mathrm{cps}, J_{2}=8.0 \mathrm{cps}\right)$ dig. $-\mathrm{C}_{2}-\mathrm{H}, 5.381 \mathrm{H}\left(\mathrm{q}, J_{1}=3.6 \mathrm{cps}, J_{2}=1.5 \mathrm{cps}\right)$ dig. $-\mathrm{C}_{4}-\mathrm{H}$. Deacetylation of II_ $100 \mathrm{mg}$ of II was deacetylated with $0.4 \mathrm{~N} \mathrm{KOH}(10 \mathrm{ml})$ under the gas flow of $\mathrm{N}_{2}$ at $50^{\circ}$ for $2 \mathrm{hr}$. The procuct (IV) was crystallized from AcOEt- $n$-hexane to give colorless needles (80 mg). mp $116^{\circ},[\alpha]_{\mathrm{D}}^{21}+6.7^{\circ}\left(c=0.75\right.$ pyridine). Anal. Calcd. for $\mathrm{C}_{15} \mathrm{H}_{28} \mathrm{O}_{8}: \mathrm{C}, 53.56 ; \mathrm{H}, 8.39$. Found: C, 53.50; $\mathrm{H}$, 8.23. IR $\nu_{\max }^{\text {Nujol }} \mathrm{cm}^{-1}: 3500(\mathrm{OH})$, ester(nil.).

Acid Hydrolysis of IV- $-100 \mathrm{mg}$ of IV was dissolved in $0.05 \mathrm{~N} \mathrm{H}_{2} \mathrm{SO}_{4}(10 \mathrm{ml})$ refluxed for $30 \mathrm{~min}$ on a water bath. After cooling, the solution was neutralized with Amberlite IR 4B. Two sugars, D-cymarose and D-digitalose, were detected by GLC, TLC and measured optical rotation. GLC: All samples were injected as their tetramethylsilylether (TMS) derivatives. (1) SE $523 \%$ : on chromosorb W, $6 \mathrm{~mm} \times 2 \mathrm{~m}$, column temp. $110^{\circ}$, injection temp. $200^{\circ}, \mathrm{N}_{2}$ flow $45 \mathrm{ml} / \mathrm{min} ; t_{\mathrm{R}}(\mathrm{min}) 11.4$ (cymarose), 17.85 (digitalose). (2) XF-1150 $5 \%$ Nitrile silicone: on Gas-chrom P, $4 \mathrm{~mm} \times 225 \mathrm{~cm}$, column temp. $80^{\circ}$, injection temp. $200^{\circ}, \mathrm{N}_{2}$ flow $90 \mathrm{ml} /$ min. $t_{\mathrm{R}}(\mathrm{min}) 12.0$ (cymarose), 13.5 (digitalose). (3) NGS $5 \%$ : on Microsorb W(60-90 mesh), $3 \mathrm{~mm} \times 3 \mathrm{~m}$, column temp. $100^{\circ}$, injection temp. $200^{\circ}, \mathrm{N}_{2}$ flow $48 \mathrm{ml} / \mathrm{min} . t_{\mathrm{R}}(\mathrm{min}) 34.8$ (cymarose), 37.0 (digitalose). TLC: plate, Kieselgel H; solvent, $\mathrm{CHCl}_{3}: \mathrm{MeOH}: \mathrm{H}_{2} \mathrm{O}=7: 3: 1$ lower layer; $R f 0.60$ (cymarose), 0.24 (digitalose). Optical rotation: D-cymarose, $[\alpha]_{\mathrm{D}}^{22}+49.2^{\circ}\left(\mathrm{c}=0.62 \mathrm{H}_{\mathrm{z}} \mathrm{O}\right)$, D-digitalose, $[\alpha]_{\mathrm{D}}^{16}+85.7^{\circ} \rightarrow+95.5^{\circ}$ (after $\left.2 \mathrm{hr}\right)\left(c=1.30 \mathrm{H}_{2} \mathrm{O}\right)$.

Permethylation of IV_- IV was permethylated by Hakomori's method for $3 \mathrm{hr}$ at room temperature. After dilution with water, the mixture was extracted with $\mathrm{CHCl}_{3}$ and the organic layer was washed with water, dried and concentrated to dryness. The residue was recrystallized from $n$-hexane to give colorless needles $(\mathrm{V}), \mathrm{mp} 106^{\circ}$. Anal. Calcd. for $\mathrm{C}_{17} \mathrm{H}_{32} \mathrm{O}_{8}: \mathrm{C}, 56.02 ; \mathrm{H}, 8.85$. Found: $\mathrm{C}, 56.17, \mathrm{H}, 8.97$. IR spectrum of $\mathrm{V}$ showed no absorption band due to hydroxyl group at $3200-3700 \mathrm{~cm}^{-1}$ region.

Acid Hydrolysis of $\mathrm{V}-\mathrm{V}$ was refluxed with $0.05 \mathrm{~N} \mathrm{H}_{2} \mathrm{SO}_{4}$ for $30 \mathrm{~min}$. D-Cymarose and 2,4-di-O-methylD-digitalose were detected by TLC and GLC. TLC: plate, Kieselgel H; solvent, (A) $\mathrm{CHCl}_{3}: \mathrm{MeOH}_{\mathrm{H}} \mathrm{H} \mathrm{O}=$ 7:3:1 lower layer, $R f 0.60$ (cymarose), 0.54(2,4-di-O-methyl-D-digitalose), (B) AcOFt, Rf 0.29 (cymarose), 0.13(2,4-di-O-methyl-D-digitalose). GLC: The same conditions used in foregoing experiments were applied. (1) $\mathrm{SE} 52, t_{\mathrm{R}}(\mathrm{min}) 11.4$ (cymarose), 8.7(2,4-di-O-methyl-D-digitalose). (2) XF 1150, $t_{\mathrm{R}}(\mathrm{min}) 12.0$ (cymarose), 6.3(2,4-di-O-methyl-D-digitalose). (3) NGS, $t_{\mathrm{R}}(\mathrm{min})$ 34.8(cymarose), 18.9(2,4-di-O-methyl-D-digitalose).

Synthesis of 2,4-Di-0-methyl-D-digitalose-95 mg of $\mathrm{D}$-fucose was permethylated by Hakomori's method and recrystallized from $n$-hexane to afford methyl 2,3,4-tri-O-methyl-D-fucoside (methyl 2,4-di-Omethyl-D-digitaloside), colorless needles, $17 \mathrm{mg}, \mathrm{mp} 101^{\circ}$ (ref. $\left.\mathrm{mp} 93-98^{\circ 20}\right)$ ). 2,4-Di-O-methyl-D-digitalose was obtained as a syrup by refluxing the product with $1 \mathrm{~N} \mathrm{H}_{2} \mathrm{SO}_{4}$ for $30 \mathrm{~min}$. $[\alpha]_{\mathrm{D}}^{19}+88^{\circ}\left(\mathrm{c}=0.37 \mathrm{H}_{2} \mathrm{O}\right)$ $\left(\right.$ ref. $\left.[\alpha]_{\mathrm{D}}+106^{\circ}\left(\mathrm{H}_{2} \mathrm{O}\right)^{20)}\right)$. It was crystallized from AcOEt-n-hexane, mp $45^{\circ}$ (ref.hydrate $\left.{ }^{20}\right) \mathrm{mp} 65^{\circ}$, anhyd. $\mathrm{mp} 36-37,{ }^{\circ 21)}[\alpha]_{\mathrm{D}}^{21}+156^{\circ} \rightarrow+128.5^{\circ}$ (ref. $[\alpha]_{\mathrm{D}}+106^{\circ 20)}$ ), anhyd. $[\alpha]_{\mathrm{D}}+183^{\circ} \rightarrow+128.8^{\circ 21)}$ ).

Permethylation of II- $100 \mathrm{mg}$ of II was permethylated by Kuhn's method at room temperature. Recrystallization of the product from AcOEt- $n$-hexane gave colorless needles $(30 \mathrm{mg})(\mathrm{VI}), \mathrm{mp} 141^{\circ},[\alpha]_{\mathrm{D}}^{21}+$ $22.5^{\circ}\left(c=0.78, \mathrm{H}_{2} \mathrm{O}\right)$, IR $\nu_{\max }^{\mathrm{ccl}} \mathrm{cm}^{-1}: \mathrm{OH}(\mathrm{nil}), 1760,1260$ (ester). Anal. Calcd. for $\mathrm{C}_{18} \mathrm{H}_{32} \mathrm{O}_{9}: \mathrm{C}, 55.09 ; \mathrm{H}$, 8.22. Found: $\mathrm{C}, 54.95 ; \mathrm{H}, 8.24$.

Acid Hydrolysis of VI- $10 \mathrm{mg}$ of VI was refluxed with $2 \mathrm{~N}$ arihydrous $\mathrm{HCl}-\mathrm{MeOH}(4 \mathrm{ml})$ for $30 \mathrm{~min}$. Methyl 4-O-methyl- $\alpha$-D-digitaloside was identified with an authentic sample ${ }^{22}$ by TLC, GLC and mixed fusion. Methyl 4-O-methyl- $\alpha$-D-digitaloside: colorless needles from petroleum ether (bp 40-60 $0^{\circ}$, sublime, $\operatorname{mp~} 105^{\circ},[\alpha]_{\mathrm{D}}^{22}+197^{\circ}\left(c=0.36 \mathrm{H}_{2} \mathrm{O}\right)$ (ref. mp $100^{\circ}$, $[\alpha]_{\mathrm{D}}-213^{\circ}$ (L-form) $\mathrm{H}_{2} \mathrm{O}^{22}$ ) . Anal. Calcd. for $\mathrm{C}_{9} \mathrm{H}_{18} \mathrm{O}_{5}$ : C, 52.41; H, 8.80. Found: C, 52.48; H, 8.75.

Oxidation of I with Bromine (Lactonization of $\mathrm{I})-\mathrm{I}(250 \mathrm{mg})$ was dissolved in water $(2 \mathrm{ml})$ and $\mathrm{Br}_{2}$ . $(50 \mu \mathrm{l})$ was added under stirring. The reaction mixture was kept at room temperature for $24 \mathrm{hr}$ in the dark. After removing excess $\mathrm{Br}_{2}$ under the gas flow of $\mathrm{N}_{2}$, a small amount of $\mathrm{Ag}_{2} \mathrm{CO}_{3}$ was added. The resulted precipitate was removed by filtration and the filtrate was concentrated in vacuo at room temperature. The residue was purified by column chromatography on silica gel $(80 \mathrm{~g})$ developed with $\mathrm{CHCl}_{3}-\mathrm{MeOH}_{-} \mathrm{H}_{2} \mathrm{O}$ $=9: 1: 1$ lower layer. 4-O-(2-O-Acetyl- $\beta$-D-digitalopyranosyl)-D-cymaronic acid lactone(VII) was crystallized from AcOEt- $n$-hexane, colorless leaflets $(80 \mathrm{mg}), \mathrm{mp} 140-141^{\circ},[\alpha]_{\mathrm{D}}^{31}+33.57^{\circ}\left(c=1.40 \mathrm{CHCl}_{3}\right)$. Anal. Calcd. for $\mathrm{C}_{16} \mathrm{H}_{26} \mathrm{O}_{9}: \mathrm{C}, 53.03 ; \mathrm{H}, 7.23$. Found: C, 53.10; H, 7.44. IR $\nu_{\max }^{\mathrm{CH}_{2} \mathrm{Cl}_{2}} \mathrm{~cm}^{-1}: 3570(\mathrm{OH}), 1740$ ( $\delta$-lactone).

Acknowledgement The authors express their gratitude to Prof. S. Shibata, Faculty of Pharmaceutical Sciences, University of Tokyo, for his encouragement throughout the course of this work.

We are grateful to Prof. T. Reichstein, Institute für Organische Chemie der Universität Basel and to Dr. J. Okano, Daiichi Seiyaku Co., Ltd. for their kind supply of the authentic samples. Thanks are also due to Dr. M. Shimizu and Dr. M. Sano, Daiichi Seiyaku Co., Ltd. for NMR spectral measurement, to the members of Analytical Laboratory of the School of Pharmaceutical Sciences, Showa University for elemental analysis.

20) Sybil P. James and F. Smith, J. Chem. Soc., 739, 746 (1945).

21) O.T. Schimidt, W. Mayer and A. Distelmaier, Ann., 555, 26 (1943).

22) E.E. Percival and E.G.V. Percival, J. Chem. Soc., 1950, 690. 